\title{
Spontaneous Intracerebral Hemorrhage: Management
}

\author{
Jun Yup Kim, Hee-Joon Bae \\ Department of Neurology, Stroke Center, Seoul National University Bundang Hospital, College of Medicine, Seoul National University, \\ Seongnam, Korea
}

\begin{abstract}
Spontaneous non-traumatic intracerebral hemorrhage (ICH) remains a significant cause of mortality and morbidity throughout the world. To improve the devastating course of $\mathrm{ICH}$, various clinical trials for medical and surgical interventions have been conducted in the last 10 years. Recent large-scale clinical trials have reported that early intensive blood pressure reduction can be a safe and feasible strategy for $\mathrm{ICH}$, and have suggested a safe target range for systolic blood pressure. While new medical therapies associated with warfarin and non-vitamin $\mathrm{K}$ antagonist oral anticoagulants have been developed to treat ICH, recent trials have not been able to demonstrate the overall beneficial effects of surgical intervention on mortality and functional outcomes. However, some patients with $\mathrm{ICH}$ may benefit from surgical management in specific clinical contexts and/or at specific times. Furthermore, clinical trials for minimally invasive surgical evacuation methods are ongoing and may provide positive evidence. Upon understanding the current guidelines for the management of ICH, clinicians can administer appropriate treatment and attempt to improve the clinical outcome of ICH. The purpose of this review is to help in the decision-making of the medical and surgical management of ICH.
\end{abstract}

Keywords Stroke; Cerebrovascular disorders; Intracranial hemorrhages; Cerebral hemorrhage; Therapeutics

\author{
Correspondence: Hee-Joon Bae \\ Department of Neurology, \\ Cerebrovascular Disease Center, Seoul \\ National University Bundang Hospital, \\ College of Medicine, Seoul National \\ University, 82 Gumi-ro 173 beon-gil, \\ Bundang-gu, Seongnam 13620, Korea \\ Tel: +82-31-787-7467 \\ Fax: +82-31-787-4059 \\ Email: braindoc@snu.ac.kr
}

Received: December 6, 2016

Revised: January 17, 2017

Accepted: January 17, 2017

The authors have no financial conflicts of interest.

\section{Introduction}

Spontaneous non-traumatic intracerebral hemorrhage (ICH) is the second most prevalent subtype of stroke and is associated with high mortality and morbidity throughout the world. ${ }^{1-3}$ Various clinical trials related to the medical and surgical management of ICH have been conducted to overcome its devastating clinical course. Despite these efforts in the past decades, there have been no dramatic advances in the development of interventions to improve the functional outcomes after $\mathrm{ICH}^{.}{ }^{4}$ In this situation, many clinicians may misunderstand that effective treatment options are lacking; however, the necessity of excellence in clinical care and research should be emphasized rather than underestimated. In this review, we discuss previous clinical trials and the current guidelines for the management of spontaneous $\mathrm{ICH}$; ongoing clinical trials are also included. For this purpose, a systematic literature review was conducted with full PubMed searches for all the English articles about the management of $\mathrm{ICH}$, regardless of the date of publication.

\section{Initial evaluation and management}

In terms of the pathogenesis of $\mathrm{ICH}$ resulting from bursting of intracerebral arteries, a majority of fatalities occur in the first two days of the onset of symptoms. ${ }^{5,6}$ Furthermore, nearly onefifth of the patients with $\mathrm{ICH}$ experience neurological deterioration in the pre-hospitalization period, ${ }_{1}^{7}$ and one-fourth of the patients in the hospitalization period. ${ }^{8}$ Rapid initial diagnosis and concentrated management are crucial in the early management of ICH. When a patient presents with focal neurological deficits, severe headache, vomiting, high systolic blood pressure (SBP) greater than $220 \mathrm{mmHg}$, and decreased consciousness with a 
sudden onset, ICH should be the first condition considered in the diagnosis. In addition to clinical presentation, a brief medical history including hypertension, prior stroke, recent head trauma, and prior use of antithrombotic drugs including anticoagulants, should also be recorded. After a quick assessment of the medical history and presentation, neuroimaging should be performed to confirm the diagnosis. Brain computed tomography (CT) is the gold standard for identifying acute hemorrhage; magnetic resonance imaging (MRI) can be an alternative with an advantage of being able to differentiate between the acute and chronic stages of hemorrhage. ${ }^{9.10}$

In addition to the initial diagnosis of $\mathrm{ICH}$ at the emergency room, acute management should be cooperated at the same time. The main principle for the early management of $\mathrm{ICH}$ is the same as that for the management of ischemic stroke. ${ }^{11}$ Airway management (if needed), cardiovascular support, urgent BP lowering treatment, and reversal of coagulation abnormalities should be initiated at the emergency room. Critical protocols developed for the management of ICH may allow more efficient, standardized, and integrated management of patients with $\mathrm{ICH}$ and reduce the length of stay at the emergency room by facilitating their prompt admission to a stroke unit or a neuroscience intensive care unit. $^{12}$

Various grading scales are used for predicting the prognosis in the early stages of $\mathrm{ICH}^{5,13-17} \mathrm{The} \mathrm{ICH}$ score is the mostly com-

Table 1. Determination of the ICH score

\begin{tabular}{lc}
\hline Component & ICH Score Points \\
\hline GCS score & \\
$3-4$ & 2 \\
$5-12$ & 1 \\
$13-15$ & 0 \\
ICH volume $\left(\mathrm{cm}^{3)}\right.$ & 1 \\
$\geq 30$ & 0 \\
$<30$ & \\
IVH & 1 \\
Yes & 0 \\
No & \\
Infratentorial origin of ICH & 1 \\
Yes & 0 \\
No & \\
Age (year) & 1 \\
$\geq 80$ & 0 \\
$<80$ & $0-6$ \\
Total ICH Score & \\
\hline
\end{tabular}

The GCS score refers to the GCS score at initial presentation (or after resuscitation); ICH volume, volume on initial CT calculated using the $\mathrm{ABC} / 2$ method; IVH, presence of any IVH on the initial CT.

GCS, Glasgow coma scale; ICH, intracerebral hemorrhage; $\mathrm{CT}$, computed tomography; IVH, intraventricular hemorrhage.

Adapted from Hemphill JC 3rd, Bonovich DC, Besmertis L, Manley GT, Johnston SC. The ICH score: a simple, reliable grading scale for intracerebral hemorrhage. Stroke 2001;32:891-897. monly used scale and can be easily calculated based on neurological examination and CT findings (Table 1). ${ }^{5}$ In prospective observational cohort studies, the ICH score could be a valid clinical grading scale for the 30-day mortality (Figure 1$)^{5}$ and 12-month functional outcome. ${ }^{15}$

\section{Medical management}

Recommendations for medical management of ICH are summarized in Table 2 and described below.

\section{Monitoring and nursing care}

The condition of patients with ICH frequently deteriorates within the first 24 or 48 hours after symptom onset because of secondary injuries caused by hematoma expansion, intraventricular hemorrhage (IVH) extension, fever, and high blood pressure. ${ }^{18-20}$ Hence, patients in the acute phase of ICH should be monitored and taken care of in facilities in which the close monitoring of the patient's status and frequent administration of medications are possible. In a prospective observational study, the patients admitted to a specialized neuroscience intensive care unit (ICU) showed reduced mortality compared to those admitted to the general ICU. ${ }^{21}$ In a Swedish cohort study with 86 hospitals and 105,043 patients, care in the stroke unit was associated with better long-term survival in patients with $\mathrm{ICH}^{22}$ Specialized care units such as the neuroscience ICU and stroke unit can provide close monitoring of blood pressure (BP), heart rate, electrocardiograph findings, oxygen saturation, and neurological status in medically and neurologically unstable patients in the early stage of ICH. The intracranial pressure (ICP), cerebral perfu-

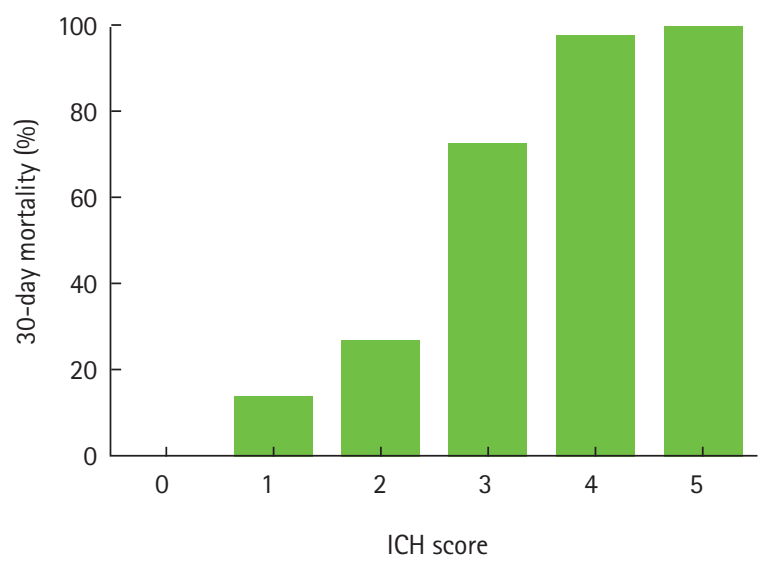

Figure 1. The ICH Score and 30-day mortality. Data were revised from Hemphill JC 3rd, Bonovich DC, Besmertis L, Manley GT, Johnston SC. The ICH score: a simple, reliable grading scale for intracerebral hemorrhage. Stroke 2001;32:891-897. There was no patient with a score of 6 in the cohort, but an ICH score of 6 would be predicted to be associated with a high risk of mortality. 
Table 2. Medical management of ICH

\begin{tabular}{|c|c|}
\hline Component & Recommendation \\
\hline \multirow[t]{2}{*}{ Blood pressure } & $\begin{array}{l}\text { For patients with SBP }>150 \mathrm{mmHg} \text { and } \leq 220 \mathrm{mmHg} \text {, early intensive BP-lowering treatment with a target of } \\
140 \mathrm{mmHg} \text { can be a safe and effective method. }\end{array}$ \\
\hline & $\begin{array}{l}\text { For patients with SBP > } 220 \mathrm{mmHg} \text {, aggressive BP reduction with a continuous intravenous infusion of BP } \\
\text { lowering drugs, such as nicardipine, should be considered. }\end{array}$ \\
\hline \multirow[t]{2}{*}{ Anticoagulation-related ICH } & Withhold anticoagulants and correct INR, if elevated, by intravenous infusion of vitamin K and FFP. \\
\hline & PCCs can be considered rather than FFP given its fewer complications and ability to rapidly correct the INR. \\
\hline Antiplatelet medication-related ICH & Consider platelet transfusions, although the evidence is unclear. \\
\hline \multirow[t]{3}{*}{ Thromboprophylaxis } & Apply intermittent pneumatic compression at admission to prevent venous thromboembolism. \\
\hline & $\begin{array}{l}\text { Low-molecular-weight heparin or unfractionated heparin can be applied after cessation of bleeding in immobile } \\
\text { patients. }\end{array}$ \\
\hline & $\begin{array}{l}\text { Systemic anticoagulation or IVC filter can be considered in patients with symptomatic DVT or pulmonary } \\
\text { thromboembolism. }\end{array}$ \\
\hline \multirow[t]{2}{*}{$\mathrm{ICP}$} & $\begin{array}{l}\text { Patients with decreased level of consciousness can be treated by ventricular drainage of the hydrocephalus, } \\
\text { if needed. }\end{array}$ \\
\hline & Hypertonic saline or mannitol can be used appropriately. \\
\hline Fever & $\begin{array}{l}\text { Fever should be treated with antipyretic medication and/or external or internal cooling methods to prevent } \\
\text { poor outcomes. }\end{array}$ \\
\hline Glucose & Regular monitoring and control of glucose is essential to prevent both hyperglycemia and hypoglycemia. \\
\hline \multirow[t]{3}{*}{ Seizure } & Clinical seizures are frequent among patients with $\mathrm{ICH}$ and should be treated. \\
\hline & Electrographic seizures with decreased level of consciousness should be treated. \\
\hline & $\begin{array}{l}\text { Continuous EEG monitoring can be beneficial in patients with depressed mental status that is not explainable } \\
\text { by hemorrhage. }\end{array}$ \\
\hline
\end{tabular}

SBP, systolic blood pressure; INR, international normalized ratio; FFP, fresh frozen plasma; PCCs, prothrombin complex concentrates; IVC, inferior vena cava; $D V T$, deep vein thrombosis; ICP, intracranial pressure; ICH, intracerebral hemorrhage; EEG, electroencephalography.

sion pressure, and continuous intra-arterial blood pressure (BP) can also be monitored.

\section{Blood pressure reduction}

Based on the viewpoint that increased BP causes greater tearing of blood vessels and flow-out of blood through these vessels and eventually leads to the expansion of the hematoma, high BP is considered to be associated with hematoma expansion and poor outcomes, especially early neurological deterioration, mortality, and dependency. ${ }^{23-25}$ Thus, intensive BP reduction is thought to reduce hematoma expansion and improve the clinical outcomes in patients with $\mathrm{ICH}$. However, the therapeutic goals of BP reduction in the early phase of $\mathrm{ICH}$ are not clearly defined. The key point to debate is whether acute $\mathrm{BP}$ reduction results in ischemic insult to perihematomal penumbral lesions surrounding the hemorrhage. ${ }^{26}$ On the other hand, a randomized clinical trial showed that rapid BP reduction targeting an SBP of $<150 \mathrm{mmHg}$ did not reduce perihematomal cerebral blood flow on CT perfusion imaging further than that targeting an SBP of $<180 \mathrm{mmHg}$. $^{27}$

Recently, a few randomized clinical trials were performed to identify therapeutic targets and evaluate the safety of intensive $\mathrm{BP}$ reduction in the early phases of $\mathrm{ICH}^{28-30}$ The pilot phase of the Intensive Blood Pressure Reduction in Acute Cerebral Hemorrhage (INTERACT 1) trial enrolled 404 patients with acute spontaneous ICH within 6 hours of symptom onset from Austra- lia, China, and South Korea. ${ }^{29}$ They compared the early intensive BP lowering group (target SBP, $140 \mathrm{mmHg}$ ) to the standard guideline-based group (target SBP, $180 \mathrm{mmHg}$ ). The primary outcome was proportional change in the hematoma volume at 24 hours. In 2008, the results showed that the mean hematoma expansion at 24 hours was greater $(P=0.04)$ in the guidelinebased group (36.3\%) than in the intensive BP lowering group $(13.7 \%) .{ }^{29,31}$ After controlling for the effects of the initial hematoma volume and the onset-to-CT time, the median hematoma expansion was $16.2 \%$ in the guideline-based group and $6.2 \%$ in the intensive BP lowering group $(P=0.06){ }^{29}$ There were no differences in the 90-day functional outcomes and adverse events between the two treatment groups. ${ }^{29}$

In 2010, the Antihypertensive Treatment of Acute Cerebral Hemorrhage (ATACH) trial reported similar results about the safety of early intensive BP lowering treatment. This study was an open-label pilot study designed to evaluate the feasibility and safety of three escalating levels of antihypertensive treatment with the intravenous administration of nicardipine in patients with $\mathrm{ICH}$-related acute hypertension. ${ }^{30}$ Patients with $\mathrm{ICH}$ and an SBP $\geq 170 \mathrm{mmHg}$ who presented within 6 hours of the onset of symptoms were enrolled. Continuous intravenous nicardipine was administered to achieve a target SBP of $170-200 \mathrm{mmHg}$ in the first group $(n=18), 140-170 \mathrm{mmHg}$ in the second group $(n=20)$, and $110-140 \mathrm{mmHg}$ in the third group $(n=22)$. The investigators 
found no significant relationship between BP reduction and any of the outcome measurements (hematoma expansion, higher perihematomal edema ratio, and poor 3-month modified Rankin scale score).

Recently, the results of the largest randomized clinical trial evaluating the efficacy of intensive BP lowering were published. ${ }^{28}$ The INTERACT 2 trial is a phase 3 trial enrolling 2,839 patients with an SBP between 150 and $220 \mathrm{mmHg}$ within 6 hours of the ICH. The participants were randomized to the intensive treatment group (target SBP, $<140 \mathrm{mmHg}$ ) or the standard treatment group (target SBP, $<180 \mathrm{mmHg}$ ). The BP lowering therapy was started within 1 hour of randomization and continued for a duration of 7 days. The investigators found that the intensive treatment group was less likely to have the primary outcome of death or major disability (modified Rankin scale score $\geq 3 ;$ OR [odds ratio], $0.87 ; 95 \% \mathrm{Cl}$ [confidence interval], 0.75 $1.01 ; P=0.06) .{ }^{4}{ }^{28}$ Ordinal analysis showed that the intensive treatment decreased the odds of higher modified Rankin scale scores (OR, 0.87; 95\% Cl, 0.77-1.00; $P=0.04) .{ }^{28}$ The incidence of nonfatal serious adverse events did not differ between the two treatment groups.

In 2016, the results of the ATACH 2 tria $\left.\right|^{32}$ were reported. The purpose of this trial was to determine the efficacy of rapidly lowering SBP in patients with $\mathrm{ICH}$ in an earlier time window than that evaluated in previous trials. A total of 1,000 patients with ICH were randomized to intensive BP lowering (target SBP, 110-139 $\mathrm{mmHg}$ ) or standard BP lowering (target SBP, 140-179 $\mathrm{mmHg}$ ). Intravenous nicardipine within 4.5 hours of the onset of symptoms was used as a method of BP reduction, which was earlier compared to the 6-hour time-point in the INTERACT 2 trial. The primary outcome of death or disability (modified Rankin scale score of 4 to 6 ) at 3 months after randomization was achieved in $38.7 \%$ of the patients in the intensive treatment group and in $37.7 \%$ of the patients in the standard treatment group (adjusted relative risk [RR], $1.04 ; 95 \% \mathrm{Cl}, 0.85-1.27$; $P=0.72)$. $^{32}$ While the incidence of hematoma expansion, defined as a $>33 \%$ increase in the $\mathrm{ICH}$ volume over the initial 24 hours after the onset of symptoms, was lower in the intensive treatment (18.9\%) group than in the standard treatment group (24.4\%), the difference between the groups was not statistically significant $(P=0.08)$. There was no significant difference in the incidence of treatment-related serious adverse events within 72 hours of the onset of symptoms.

Overall, the current evidence supports that early intensive BP lowering is safe and feasible, and is associated with a modestly better functional outcome. The 2015 American Heart Association/American Stroke Association guidelines for the management of spontaneous $\mathrm{ICH}$ recommend early BP reduction with an SBP target of $140 \mathrm{mmHg}$ for patients with ICH presenting with an SBP between 150 and $220 \mathrm{mmHg}$ and without any contraindication to acute BP treatment. ${ }^{4}$ For patients with $\mathrm{ICH}$ presenting with an SBP $>220 \mathrm{mmHg}$, aggressive BP reduction with continuous intravenous infusion and frequent BP monitoring may be reasonable.

\section{Anticoagulation-related intracerebral hemorrhage}

The clinical outcomes of vitamin $\mathrm{K}$ antagonists (VKA)-related ICH are poor. Therefore, in addition to stopping VKA, urgent measures are usually needed to reverse the effects of VKA in patients with an elevated international normalized ratio (INR). ${ }^{2}$ Intravenous vitamin $\mathrm{K}$ administration at a dose of 5-10 $\mathrm{mg}$ should be initiated in the first hours of symptom presentation. Freshfrozen plasma, along with vitamin $K_{1}$ has been used for the rapid correction of INR for years. Recently, prothrombin complex concentrates (PCCs), activated PCC factor VIII inhibitor bypassing activity (FEIBA), and recombinant activated factor VIla (rFVIla) have been evaluated as potentially more effective alternatives. ${ }^{4}$

Reversal of non-vitamin $\mathrm{K}$ antagonist oral anticoagulants (NOACs)-related ICH has been poorly evaluated. Recently, idarucizumab, a monoclonal antibody designed for the reversal of anticoagulant effects of dabigatran, has been introduced into medical practice as the first antidote for NOACs. ${ }^{33,34}$ Furthermore, hemodialysis can be used in case of dabigatran. ${ }^{35}$ Andexanet alfa, a specific reversal agent to neutralize the anticoagulant effects of factor Xa inhibitors such as rivaroxaban, apixaban, and edoxaban, is presently in phase III clinical trials. ${ }^{35-37}$ Potential reversal strategies using FEIBA, other PCCs, rFVlla, or activated charcoal might be considered. ${ }^{4,35}$

In contrast to VKA, NOACs do not require hematological monitoring because they have different effects and sensitivities on screening coagulation tests including the prothrombin time (PT), activated partial thromboplastin time (aPT), and thrombin clotting time (T). ${ }^{38,39}$ Residual effects of NOACs can be estimated based on the elimination half-life of each NOAC and the renal function of individuals on NOACs. ${ }^{39}$ When the NOAC status of the patient is unknown, a coagulation assay can be performed to estimate the presence and concentration of NOACs in the body. Dabigatran is a direct thrombin inhibitor, and a high aPT at trough may be associated with a higher risk of bleeding, and a normal aPTT in dabigatran-treated patients has been used in emergency situations to exclude any residual anticoagulant effect. ${ }^{39-42}$ Rivaroxaban, a direct factor Xa inhibitor, can prolong the PT significantly. ${ }^{43}$ Apixaban, another direct factor $X a$ inhibitor, may be associated with prolonged PT and aPT, but normal PT and aPTT do not rule out significant anticoagulant effects. ${ }^{39}$ Thus, a drug-specific anti-factor $X$ a chromogenic assay is necessary. ${ }^{44}$ 
As the optimal timing for resumption of anticoagulation after anticoagulation-related ICH is unknown, the risk of both cardioembolic events and recurrent anticoagulation-related ICH should be considered together in determining the starting time of anticoagulation. ${ }^{45,46}$ In general, resumption of VKA within the first month is associated with a high risk of recurrent ICH. ${ }^{47}$ Therefore, a delay of at least 1 month should be suggested in patients with VKA-related ICH. ${ }^{4}$ However, early resumption of anticoagulation may be needed in patients with prosthetic heart valves because of the high risk of cardioembolic events. ${ }^{4}$ In patients with lobar $\mathrm{ICH}$, resumption of anticoagulation is reported to be associated with higher risk of recurrent ICH compared with deep hemispheric hemorrhage (1-year risk of recurrence, 15\% versus 2.1\%). ${ }^{48,49}$ Therefore, avoidance of long-term anticoagulation with VKA as a treatment for nonvalvular atrial fibrillation is probably recommended in patients with VKA-associated lobar $\mathrm{ICH}^{4}$ The safety of antiplatelet agents as alternatives to VKA in patients with lobar ICH is controversial. ${ }^{50,51}$ In patients with nonlobar ICH, antiplatelet monotherapy can be a safer alternative to VKA in some patients with atrial fibrillation. ${ }^{4,51,52}$ As alternatives to VKA after ICH, the usefulness of NOACs including dabigatran, rivaroxaban, and apixaban, remains unknown. ${ }^{4,53-55}$

\section{Antiplatelet medication-related intracerebral hemorrhage}

The effect of antiplatelet drugs on the outcome of ICH is uncertain. Two observational studies showed that reduced platelet activity is associated with IVH, death, early ICH growth, and poor functional outcome. ${ }^{56,57}$ Another study reported that the use of antiplatelet medication at the onset of ICH symptoms was not associated with increased hemorrhage volume, hematoma expansion, or poor functional outcome. ${ }^{58}$ Platelet transfusion might be considered in patients with acute ICH with prior antiplatelet use or platelet dysfunction, although there has been no randomized controlled trial testing this. Two trials on platelet transfusion in patients with $\mathrm{ICH}$ are ongoing. ${ }^{2.59}$

\section{Thromboprophylaxis in intracerebral hemorrhage}

Thromboprophylaxis in patients with acute ICH is a complicated problem. The risk of bleeding is not low, and the risk of venous thromboembolism is high. Therefore, thromboprophylaxis should not be delayed. ${ }^{4}$ The incidence of symptomatic venous thromboembolism ranges from $0.5 \%$ to $13 \%$, while that of pulmonary embolism ranges from $0.7 \%$ to $5 \% .{ }^{60}$ Methods for thromboprophylaxis were suggested through 3 different trials termed the CLOTS trials (Clots in Legs or Stockings After Stroke) I-III. ${ }^{61-64}$ The results suggested that intermittent pneumatic compression started as early as the day of hospitalization could reduce the occurrence of proximal deep vein thrombosis (DVT), and that graduated compression stockings were not effective.

Systemic anticoagulation or inferior vena cava (IVC) filter placement are probably indicated in patients with ICH with symptomatic DVT or pulmonary embolism. ${ }^{4}$ One meta-analysis found that early anticoagulation, including low-molecularweight heparin or unfractionated heparin or heparinoids, is associated with a significant reduction in pulmonary embolism and a non-significant increase in hematoma enlargement. ${ }^{65} \mathrm{An}$ IVC filter is usually not recommended in patients with acute DVT of the leg in addition to anticoagulant therapy. However, if anticoagulation therapy is contraindicated, an IVC filter can be used. ${ }^{66}$

\section{ICP and cerebral edema management}

Intracranial hypertension following $\mathrm{ICH}$ is common, especially in younger patients with supratentorial hemorrhage. ${ }^{67}$ The most common causes of intracranial hypertension are hydrocephalus from IVH and surrounding edema from hematoma. Hence, ICP monitoring and management should be considered in patients with large hematomas or those at high risk for hydrocephalus, such as patients with a Glasgow coma scale (GCS) score of $\leq 8$, clinical evidence of transtentorial herniation, or significant IVH or hydrocephalus. ${ }^{4}$ ICP can be measured by catheterization into the cerebral ventricles or brain parenchyma. The decision to use these catheters should be based on whether there is a need to drain the cerebrospinal fluid to treat the hydrocephalus or elevated ICP. In case of patients with hydrocephalus and decreased consciousness, ventricular catheterization and drainage is a reasonable method for ICP monitoring and management.

Methods for the medical management of ICP consist of head elevation to $30^{\circ}$, hyperventilation, mild sedation, and hyperosmolar therapy with hypertonic saline or mannitol. Mannitol can be administered intravenously, but special attention should be paid to volume depletion. Although hypertonic saline may require a central venous catheter, it can be more effective. ${ }^{68}$ Corticosteroids should be avoided because of their significant harmful effects such as infections without demonstrable beneficial effects. ${ }^{69}$

\section{Fever and temperature control}

The incidence of fever after supratentorial ICH is high, especially in patients with ventricular hemorrhage. Fever has been reported to worsen the outcomes in patients with ICH. In patients who survive the first 72 hours after hospitalization, the duration of fever is associated with poor functional outcome and seems to be an independent prognostic factor. ${ }^{70}$ Therefore, temperature should be regularly measured in patients with $\mathrm{ICH}$. Antipyretics are typically a simple method to reduce mild fever. External cooling devices and intravascular cold saline infusion can 
be used in different clinical settings. Preliminary studies have suggested that therapeutic cooling may reduce perihematomal edema. ${ }^{71,72}$ Treatment with mild hypothermia in $\mathrm{ICH}$ should be considered investigational at this time. Although the beneficial effect of fever treatment has not been demonstrated in patients with $\mathrm{ICH}$, maintenance of normothermia is reasonable and recommended in order to reduce secondary brain injury.

\section{Glucose management}

Hyperglycemia on admission is associated with an increased 28-day case fatality in both nondiabetic and diabetic patients with $\mathrm{ICH}^{73}$ Therefore, hyperglycemia should be controlled adequately. On the other hand, tight glucose control with intensive insulin therapy is also reported to be associated with reduced cerebral extracellular glucose availability and increased mortality. ${ }^{74,75}$ Therefore, glucose level should be monitored regularly and both hyperglycemia and hypoglycemia should be avoided. ${ }^{4}$

\section{Seizure management}

Studies using continuous electroencephalography (EEG) showed that electrographic seizures occurred in up to one third of the patients with $\mathrm{ICH}^{76-78}$ Clinical seizures are as frequent as 16\% within 1 week after ICH and the location of the hematoma influences this frequency; cortical involvement is a crucial risk factor of early seizures. ${ }^{76,79,80}$ Although the association between electrographic seizures and clinical outcomes is unclear, there is a consensus that both clinical seizures and electrographic seizures with decreased consciousness should be treated. In the case that patients with $\mathrm{ICH}$ presenting with decreased mental status of unknown etiology, continuous EEG monitoring is essential to detect electrographic seizures. With respect to the prophylactic use of antiepileptic drugs for $\mathrm{ICH}_{\text {, there is no evidence }}$ supporting their beneficial effects. Therefore, the prophylactic use of antiepileptic drugs is not recommended. ${ }^{4}$

\section{Medical complications}

The frequency of medical complications after ICH was reported in a randomized clinical trial of the safety of neuroprotectant use in patients with $\mathrm{ICH}$. The most common medical complications were pneumonia (5.7\%), pulmonary embolism (2.3\%), respiratory failure (2.0\%), aspiration pneumonia (2.0\%), sepsis (1.3\%), and urinary tract infection (0.7\%). ${ }^{81}$ Among medical complications, pulmonary complications including pneumonia, neurogenic pulmonary edema, and pulmonary embolism were seen to be the most frequent complications. One retrospective cohort study reported that one-third of the patients with $\mathrm{ICH}$ developed pulmonary complications. ${ }^{82}$ Since dysphagia and aspiration are crucial risk factors for pneumonia, formal screening for dysphagia may reduce the risk of development of pneumonia in patients with ischemic stroke. ${ }^{83}$ Other medical complications in patients with $\mathrm{ICH}$ include cardiac events and death caused by acute myocardial infarction, heart failure, ventricular arrhythmias, cardiac arrest, acute kidney failure, hyponatremia, gastrointestinal bleeding, and post-stroke depression. ${ }^{4}$ As medical complications are associated with high risk of mortality in patients with ICH usually after 7 days of hospitalization, ${ }^{4}$ comprehensive screening, monitoring, and appropriate care for each medical complication should accompany the standard management regime for $\mathrm{ICH}$.

\section{Palliative care and withdrawal of technological} support

The importance of palliative care and withdrawal of technological support has recently been highlighted. The American Heart Association/American Stroke Association have published a scientific statement addressing these issues in patients with stroke. ${ }^{84}$ The withdrawal of technological support including DoNot-Resuscitate (DNR) orders must be considered at an individual level. There is no single accurate predictor of clinical outcomes of ICH that can be helpful in determining whether withdrawal of technological support is appropriate. Most fatalities following ICH occur within the first two days, and DNR orders are recommended to be postponed until at least the second full day of hospitalization. ${ }^{4}$ The DNR status should not limit appropriate medical and surgical interventions, unless explicitly indicated by the patient or her/his family. ${ }^{4}$

\section{Surgical management}

\section{Infratentorial hemorrhage}

Emergent surgery is strongly recommended in patients with a cerebellar hemorrhage with symptoms of neurological deterioration. Because the posterior fossa has little free space, cerebellar hemorrhage easily brings about brainstem compression, ventricular obstruction, hydrocephalus, and eventually high fatality. Patients with a cerebellar hemorrhage $>3 \mathrm{~cm}$ in diameter or patients in whom cerebellar hemorrhage is causing brainstem compression or hydrocephalus can get better outcomes with surgical decompression through hematoma evacuation. ${ }^{4,85,86}$ Initial treatment of cerebellar hemorrhage with ventricular drainage alone rather than surgical evacuation is not recommended due to insufficiency for ICP control. ${ }^{4}$

As hematoma evacuation of a brainstem hemorrhage may be harmful in many cases, brainstem hemorrhage is usually managed conservatively. ${ }^{4,87,88}$ Although there are several reports, which suggest that surgical treatment is effective in managing 
brainstem hemorrhages, ${ }^{89-91}$ the role of surgical management in treating brainstem hemorrhages remains controversial.

\section{Supratentorial hemorrhage}

The beneficial effects of surgical management of supratentorial ICH remain controversial and should be restricted in specific situations. Although several randomized trials have compared the efficacy of surgical management and conservative medical management, they have not shown significant benefits of surgical management on mortality or functional outcomes. ${ }^{92,93}$

The International Surgical Trial in Intracerebral Hemorrhage (STICH) was conducted to prove the superiority of early hematoma evacuation (within 24 hours of randomization) over conservative medical treatment. ${ }^{92} \mathrm{~A}$ total of 1,033 patients were enrolled from 83 centers in 27 countries, and were randomized into early surgery $(n=503)$ or initial conservative treatment $(n=530)$ groups. The primary outcome measure was the score on the 8-point extended Glasgow outcome scale at 6 months. Of the 468 patients randomized to the early surgery group, $26 \%$ had favorable outcomes, compared to $24 \%$ of the 496 patients randomized to the initial conservative treatment group $(\mathrm{OR}, 0.89$; 95\% Cl, 0.66-1.19; $P=0.414)$. The 6-month mortality rate for the early surgery group was $36 \%$, compared with $37 \%$ for the initial conservative treatment group $(\mathrm{OR}, 0.95 ; 95 \% \mathrm{Cl}, 0.73-$ 1.23; $P=0.707)$. Subgroup analysis revealed that patients with lobar hemorrhages within $1 \mathrm{~cm}$ of the cortical surface might benefit from surgery, while patients who presented as comatose (GCS score $\leq 8$ ) showed poorer outcomes following surgery. In this STICH trial, it was suggested that early surgery could be beneficial in certain patients with superficial lobar hemorrhages, but there was no overall statistically significant difference in the mortality or functional outcome between the early surgery and initial conservative treatment groups.

In 2013, the results of the STICH II trial were published. ${ }^{93}$ The STICH II trial compared the outcomes of early surgery and initial conservative treatment in conscious patients with superficial lobar hemorrhage of 10-100 mL within $1 \mathrm{~cm}$ of the cortical surface, with no IVH, and who were admitted within 48 hours of the onset of symptoms. A total of 601 patients were enrolled from 78 centers in 27 countries, and were randomized into the early surgery $(n=307)$ or initial conservative treatment $(n=294)$ groups. The primary outcome was a prognosis-based dichotomized (favorable or unfavorable) outcome on the 8-point extended Glasgow outcome scale at 6 months. Fifty-nine percent of the patients in the early surgery group had an unfavorable outcome, compared with $62 \%$ of the patients in the initial conservative treatment group $(\mathrm{OR}, 0.86 ; 95 \% \mathrm{Cl}, 0.62-1.20 ; P=$ 0.367 ). The 6 -month mortality rate was $18 \%$ in the early surgery group and 24\% in the initial conservative treatment group (OR, $0.71 ; 95 \% \mathrm{Cl}, 0.48-1.06 ; P=0.095) .^{93}$ Thus, these two large randomized trials failed to prove the benefit of early surgical management with hematoma evacuation over initial conservative treatment. Hematoma evacuation might be considered as a lifesaving measure in patients with supratentorial hemorrhage showing neurological deterioration. ${ }^{4}$

Previous studies have reported that patients with a GCS score $<8$, significant midline shift, large hematomas, or medically intractable ICP might benefit from decompressive craniectomy. ${ }^{94-97}$ Therefore, despite the failure of large clinical trials, it should be noted that decompressive surgery with or without hematoma evacuation might be helpful in reducing the mortality rate in these specific situations. ${ }^{4}$

The role of minimally invasive surgical evacuation of $\mathrm{ICH}$ with stereotactic or endoscopic aspiration is unclear. Several studies have suggested that minimally invasive surgical evacuation might be less invasive and have better outcomes compared to a craniotomy approach. ${ }^{98-101}$ In a randomized clinical trial conducted in China, needle aspiration of basal ganglia hemorrhages improved the 3-month functional outcome without significant improvement in mortality rate, compared to medical management alone. ${ }^{101}$ Recently, the Minimally Invasive Surgery Plus Recombinant Tissue-Type Plasminogen Activator for ICH Evacuation Trial II (MISTIE II) reported a significant reduction in perihematomal edema in the hematoma evacuation group..$^{100}$ MISTIE III, a randomized phase 3 clinical trial, is ongoing.

\section{Timing of decompressive surgery}

On the basis of the subgroup analysis performed in the STICH II trial, surgery, if needed, should be considered within 21 hours of ictus for better outcomes. ${ }^{493}$ One meta-analysis indicated that there was improved outcome with surgery if randomization was undertaken within 8 hours of ictus. ${ }^{102}$ Another prospective study reported that surgical hematoma evacuation within 4 hours of ictus was complicated by rebleeding, indicating difficulty with hemostasis. ${ }^{103}$ Although more evidence is needed to determine the timing of surgery, surgical management should not be delayed if patients show neurological deterioration, and surgical management can be beneficial. The possible indications for the surgical management of $\mathrm{ICH}$ are described in Table 3.

\section{Intraventricular hemorrhage}

IVH is usually related to deep-seated ICH in the basal ganglia and/or thalamus. IVH is a crucial determinant of poor outcomes in patients with $\mathrm{ICH}^{104}$ Recently, ventricular catheter insertion with thrombolytic agents has been studied to overcome the inefficiency and difficulty of maintaining catheter patency. The 
Table 3. Surgical candidates for ICH

\begin{tabular}{ll}
\hline Situation & Surgical management \\
\hline Cerebellar hemorrhage with neurological deterioration associated with brainstem compression or hydrocephalus & Hematoma evacuation \\
Supratentorial hemorrhage with neurological deterioration & Hematoma evacuation \\
$\begin{array}{l}\text { Supratentorial hemorrhage with GCS score }<8 \text {, significant midline shift and large hematomas, medically } \\
\text { intractable ICP }\end{array}$ & Decompressive craniectomy \\
Hydrocephalus with or without IVH & Ventricular drainage \\
\hline
\end{tabular}

ICH, intracerebral hemorrhage; GCS, Glasgow coma scale; ICP, intracranial pressure; IVH, intraventricular hemorrhage.

CLEAR-IVH trial (Clot Lysis: Evaluating Accelerated Resolution of IVH) compared treatments with recombinant tissue-type plasminogen activator (rtPA) and placebo in patients with IVH attributable to spontaneous $\mathrm{ICH} .{ }^{105,106}$ Patients treated with rtPA had lower ICP and less frequent ventricular obstruction. The symptomatic rebleeding rate was not significantly different between the two groups (12\% in the rtPA group, 5\% in the placebo group, $P=0.33$ ); the median 30 -day modified Rankin scale score and mortality did not differ either. While rtPA seemed to have an acceptable safety profile in the treatment of ICH with $\mathrm{IVH}$, its efficacy and safety remain uncertain. ${ }^{4}$ Data from a welldesigned phase III clinical trial, such as CLEAR III, will be needed to fully evaluate the safety and efficacy of this treatment.

\section{Rehabilitation}

Rehabilitation is strongly recommended in patients who have survived the acute stage of $\mathrm{ICH}$ but are discharged from acute care hospitals with disability. The main principles of rehabilitation for patients with $\mathrm{ICH}$ are similar to those for patients with ischemic stroke. ${ }^{4}$ It has been repeatedly reported that the improvement of functional outcome was significantly greater in patients receiving rehabilitation compared with those receiving standard medical care. ${ }^{107,108}$ On the basis of our knowledge about stroke recovery, rehabilitation is recommended to be started as early as possible and should be continued in the community as part of a well-coordinated program of accelerated hospital discharge and home-based resettlement to promote ongoing recovery. ${ }^{4}$

\section{Conclusion}

In conclusion, in order to overcome the high mortality and morbidity, it is recommended that patients with spontaneous ICH should be taken care of in well-organized specialized stroke care facilities with a multidisciplinary team approach. All the management principles including the close monitoring of vital signs and neurological status, rapid and adequate BP correction, proper ICP control and timely surgical management of selected patients, prevention of complications, and early rehabilitation are important for better clinical outcomes.

\section{References}

1. Feigin VL, Lawes CM, Bennett DA, Barker-Collo SL, Parag V. Worldwide stroke incidence and early case fatality reported in 56 population-based studies: a systematic review. Lancet Neurol 2009;8:355-369.

2. Steiner T, Al-Shahi Salman R, Beer R, Christensen $H_{1}$ Cordonnier $C$, Csiba $L$, et al. European Stroke Organisation (ESO) guidelines for the management of spontaneous intracerebral hemorrhage. Int J Stroke 2014;9:840-855.

3. van Asch CJ, Luitse MJ, Rinkel GJ, van der Tweel I, Algra A, Klijn CJ. Incidence, case fatality, and functional outcome of intracerebral haemorrhage over time, according to age, sex, and ethnic origin: a systematic review and meta-analysis. Lancet Neurol 2010;9:167-176.

4. Hemphill JC 3rd, Greenberg SM, Anderson CS, Becker K, Bendok BR, Cushman $M$, et al. Guidelines for the management of spontaneous intracerebral hemorrhage: a guideline for healthcare professionals from the American Heart Association/American Stroke Association. Stroke 2015;46:2032-2060.

5. Hemphill JC 3rd, Bonovich DC, Besmertis L, Manley GT, Johnston SC. The ICH score: a simple, reliable grading scale for intracerebral hemorrhage. Stroke 2001;32:891-897.

6. Mayer SA, Rincon F. Treatment of intracerebral haemorrhage. Lancet Neurol 2005;4:662-672.

7. Moon JS, Janjua N, Ahmed S, Kirmani JF, Harris-Lane P, Jacob $M$, et al. Prehospital neurologic deterioration in patients with intracerebral hemorrhage. Crit Care Med 2008;36:172-175.

8. Fan JS, Huang HH, Chen YC, Yen DH, Kao WF, Huang MS, et al. Emergency department neurologic deterioration in patients with spontaneous intracerebral hemorrhage: incidence, predictors, and prognostic significance. Acad Emerg Med 2012; 19:133-138.

9. Chalela JA, Kidwell CS, Nentwich LM, Luby M, Butman JA, Demchuk AM, et al. Magnetic resonance imaging and computed tomography in emergency assessment of patients with 
suspected acute stroke: a prospective comparison. Lancet 2007;369:293-298.

10. Fiebach JB, Schellinger PD, Gass A, Kucinski T, Siebler M, Villringer $A$, et al. Stroke magnetic resonance imaging is accurate in hyperacute intracerebral hemorrhage: a multicenter study on the validity of stroke imaging. Stroke 2004;35:502506.

11. Jauch EC, Saver JL, Adams HP Jr, Bruno A, Connors JJ, Demaerschalk $B M$, et al. Guidelines for the early management of patients with acute ischemic stroke: a guideline for healthcare professionals from the American Heart Association/ American Stroke Association. Stroke 2013;44:870-947.

12. Andrews CM, Jauch EC, Hemphill JC 3rd, Smith WS, Weingart SD. Emergency neurological life support: intracerebral hemorrhage. Neurocrit Care 2012;17 Suppl 1:S37-46.

13. Bernstein RA, Hemphill JC. Critical care of acute ischemic stroke. Curr Neurol Neurosci Rep 2001;1:587-592.

14. Bruce SS, Appelboom G, Piazza M, Hwang BY, Kellner C, Carpenter $\mathrm{AM}$, et al. A comparative evaluation of existing grading scales in intracerebral hemorrhage. Neurocrit Care 2011;15: 498-505.

15. Hemphill JC 3rd, Farrant M, Neill TA Jr. Prospective validation of the ICH Score for 12-month functional outcome. Neurology 2009;73:1088-1094.

16. Ji $R$, Shen $H$, Pan $Y$, Wang $P$, Liu $G$, Wang $Y$, et al. A novel risk score to predict 1-year functional outcome after intracerebral hemorrhage and comparison with existing scores. Crit Care 2013;17:R275.

17. Rost NS, Smith EE, Chang Y, Snider RW, Chanderraj R, Schwab $\mathrm{K}$, et al. Prediction of functional outcome in patients with primary intracerebral hemorrhage: the FUNC score. Stroke 2008;39:2304-2309.

18. Sun W, Pan W, Kranz PG, Hailey CE, Williamson RA, Sun W, et al. Predictors of late neurological deterioration after spontaneous intracerebral hemorrhage. Neurocrit Care 2013;19:299305.

19. Leira R, Davalos A, Silva Y, Gil-Peralta A, Tejada J, Garcia M, et al. Early neurologic deterioration in intracerebral hemorrhage: predictors and associated factors. Neurology 2004;63:461467.

20. Sorimachi T, Fujii Y. Early neurological change in patients with spontaneous supratentorial intracerebral hemorrhage. J Clin Neurosci 2010;17:1367-1371.

21. Diringer MN, Edwards DF. Admission to a neurologic/neurosurgical intensive care unit is associated with reduced mortality rate after intracerebral hemorrhage. Crit Care Med 2001; 29:635-640.

22. Terent $A$, Asplund $K$, Farahmand B, Henriksson KM, Norrving
B, Stegmayr B, et al. Stroke unit care revisited: who benefits the most? A cohort study of 105,043 patients in Riks-Stroke, the Swedish Stroke Register. J Neurol Neurosurg Psychiatry 2009;80:881-887.

23. Rodriguez-Luna $D$, Pineiro $S$, Rubiera $M$, Ribo $M$, Coscojuela $P$, Pagola J, et al. Impact of blood pressure changes and course on hematoma growth in acute intracerebral hemorrhage. Eur J Neurol 2013;20:1277-1283.

24. Sakamoto Y, Koga M, Yamagami H, Okuda S, Okada Y, Kimura $\mathrm{K}$, et al. Systolic blood pressure after intravenous antihypertensive treatment and clinical outcomes in hyperacute intracerebral hemorrhage: the stroke acute management with urgent risk-factor assessment and improvement-intracerebral hemorrhage study. Stroke 2013;44:1846-1851.

25. Zhang Y, Reilly KH, Tong W, Xu T, Chen J, Bazzano LA, et al. Blood pressure and clinical outcome among patients with acute stroke in Inner Mongolia, China. J Hypertens 2008;26: 1446-1452.

26. Naval NS, Nyquist PA, Carhuapoma JR. Management of spontaneous intracerebral hemorrhage. Neurol Clin 2008;26:373384 , vii.

27. Butcher KS, Jeerakathil T, Hill M, Demchuk AM, Dowlatshahi $D$, Coutts SB, et al. The intracerebral hemorrhage acutely decreasing arterial pressure trial. Stroke 2013;44:620-626.

28. Anderson CS, Heeley E, Huang Y, Wang J, Stapf $C_{\text {, Delcourt }} C_{\text {, }}$ et al. Rapid blood-pressure lowering in patients with acute intracerebral hemorrhage. N Engl J Med 2013;368:23552365.

29. Anderson CS, Huang $Y$, Wang JG, Arima $H$, Neal $B$, Peng $B$, et al. Intensive blood pressure reduction in acute cerebral haemorrhage trial (INTERACT): a randomised pilot trial. Lancet Neurol 2008;7:391-399.

30. Qureshi Al, Palesch YY, Martin R, Novitzke J, Cruz-Flores $S$, Ehtisham $A$, et al. Effect of systolic blood pressure reduction on hematoma expansion, perihematomal edema, and 3-month outcome among patients with intracerebral hemorrhage: results from the antihypertensive treatment of acute cerebral hemorrhage study. Arch Neurol 2010;67:570-576.

31. Adeoye 0 , Broderick JP. Advances in the management of intracerebral hemorrhage. Nat Rev Neurol 2010;6:593-601.

32. Qureshi Al, Palesch YY, Barsan WG, Hanley DF, Hsu CY, Martin $\mathrm{RL}$, et al. Intensive blood-pressure lowering in patients with acute cerebral hemorrhage. N Engl J Med 2016;375:10331043.

33. Eikelboom JW, Quinlan DJ, van Ryn J, Weitz Jl. Idarucizumab: the antidote for reversal of dabigatran. Circulation 2015;132: 2412-2422.

34. Pollack CV Jr, Reilly PA, Eikelboom J, Glund S, Verhamme P, 
Bernstein RA, et al. Idarucizumab for dabigatran reversal. $N$ Engl J Med 2015;373:511-520.

35. Schreuder FH, Sato S, Klijn CJ, Anderson CS. Medical management of intracerebral haemorrhage. J Neurol Neurosurg Psychiatry 2017;88:76-84.

36. Connolly SJ, Milling TJ Jr, Eikelboom JW, Gibson CM, Curnutte JT, Gold A, et al. Andexanet alfa for acute major bleeding associated with factor Xa inhibitors. N Engl J Med 2016;375: 1131-1141.

37. Siegal DM, Curnutte JT, Connolly SJ, Lu G, Conley PB, Wiens $B \mathrm{~L}$, et al. Andexanet alfa for the reversal of factor $\mathrm{Xa}$ inhibitor activity. N Engl J Med 2015;373:2413-2424.

38. Konkle BA. Monitoring target specific anticoagulants. J Thromb Thrombolysis 2013;35:387-390.

39. Tran $H_{1}$ Joseph J, Young L, McRae S, Curnow J, Nandurkar $H_{\text {, }}$ et al. New oral anticoagulants: a practical guide on prescription, laboratory testing and peri-procedural/bleeding management. Australasian Society of Thrombosis and Haemostasis. Intern Med J 2014;44:525-536.

40. Douxfils J, Mullier F, Robert S, Chatelain C, Chatelain B, Dogne JM. Impact of dabigatran on a large panel of routine or specific coagulation assays. Laboratory recommendations for monitoring of dabigatran etexilate. Thromb Haemost 2012; 107:985-997.

41. Harenberg J, Giese C, Marx S, Kramer R. Determination of dabigatran in human plasma samples. Semin Thromb Hemost 2012;38:16-22.

42. Lindahl TL, Baghaei F, Blixter IF, Gustafsson KM, Stigendal L, Sten-Linder $M$, et al. Effects of the oral, direct thrombin inhibitor dabigatran on five common coagulation assays. Thromb Haemost 2011;105:371-378.

43. Harenberg J, Erdle S, Marx S, Kramer R. Determination of rivaroxaban in human plasma samples. Semin Thromb Hemost 2012;38:178-184.

44. Douxfils J, Chatelain C, Chatelain B, Dogne JM, Mullier F. Impact of apixaban on routine and specific coagulation assays: a practical laboratory guide. Thromb Haemost 2013;110:283294.

45. Kuramatsu JB, Gerner ST, Schellinger PD, Glahn J, Endres M, Sobesky J, et al. Anticoagulant reversal, blood pressure levels, and anticoagulant resumption in patients with anticoagulation-related intracerebral hemorrhage. JAMA 2015;313:824836.

46. Poli D, Antonucci E, Dentali F, Erba N, Testa S, Tiraferri E, et al. Recurrence of $\mathrm{ICH}$ after resumption of anticoagulation with VK antagonists: CHIRONE study. Neurology 2014;82:10201026.

47. Majeed A, Kim YK, Roberts RS, Holmstrom M, Schulman S.
Optimal timing of resumption of warfarin after intracranial hemorrhage. Stroke 2010;41:2860-2866.

48. Eckman MH, Rosand J, Knudsen KA, Singer DE, Greenberg SM. Can patients be anticoagulated after intracerebral hemorrhage? A decision analysis. Stroke 2003;34:1710-1716.

49. Schulman S. Resumption of oral anticoagulation after warfarin-associated intracerebral hemorrhage: no. Stroke 2011;42: 3663-3664.

50. Biffi A, Halpin A, Towfighi A, Gilson A, Busl $K$, Rost $N$, et al. Aspirin and recurrent intracerebral hemorrhage in cerebral amyloid angiopathy. Neurology 2010;75:693-698.

51. Flynn RW, MacDonald TM, Murray GD, MacWalter RS, Doney AS. Prescribing antiplatelet medicine and subsequent events after intracerebral hemorrhage. Stroke 2010;41:2606-2611.

52. Investigators A, Connolly SJ, Pogue J, Hart RG, Hohnloser SH, Pfeffer $M$, et al. Effect of clopidogrel added to aspirin in patients with atrial fibrillation. N Engl J Med 2009;360:20662078.

53. Connolly SJ, Ezekowitz MD, Yusuf S, Eikelboom J, Oldgren J, Parekh $A$, et al. Dabigatran versus warfarin in patients with atrial fibrillation. N Engl J Med 2009;361:1139-1151.

54. Granger CB, Alexander JH, McMurray JJ, Lopes RD, Hylek EM, Hanna $M$, et al. Apixaban versus warfarin in patients with atrial fibrillation. N Engl J Med 2011;365:981-992.

55. Patel MR, Mahaffey KW, Garg J, Pan G, Singer DE, Hacke W, et al. Rivaroxaban versus warfarin in nonvalvular atrial fibrillation. N Engl J Med 2011;365:883-891.

56. Naidech AM, Bernstein RA, Levasseur K, Bassin SL, Bendok $\mathrm{BR}$, Batjer $\mathrm{HH}$, et al. Platelet activity and outcome after intracerebral hemorrhage. Ann Neurol 2009;65:352-356.

57. Naidech AM, Jovanovic B, Liebling S, Garg RK, Bassin SL, Bendok $B R$, et al. Reduced platelet activity is associated with early clot growth and worse 3-month outcome after intracerebral hemorrhage. Stroke 2009;40:2398-2401.

58. Sansing LH, Messe SR, Cucchiara BL, Cohen SN, Lyden PD, Kasner SE, et al. Prior antiplatelet use does not affect hemorrhage growth or outcome after ICH. Neurology2009;72:13971402.

59. de Gans K, de Haan RJ, Majoie CB, Koopman MM, Brand A, Dijkgraaf MG, et al. PATCH: platelet transfusion in cerebral haemorrhage: study protocol for a multicentre, randomised, controlled trial. BMC Neurol 2010;10:19.

60. Chan S, Hemphill JC 3rd. Critical care management of intracerebral hemorrhage. Crit Care Clin 2014;30:699-717.

61. Collaboration CT. Thigh-length versus below-knee stockings for deep venous thrombosis prophylaxis after stroke: a randomized trial. Ann Intern Med 2010;153:553-562.

62. Collaboration CT, Dennis M, Sandercock P, Reid J, Graham C, 
Forbes J, et al. Effectiveness of intermittent pneumatic compression in reduction of risk of deep vein thrombosis in patients who have had a stroke (CLOTS 3): a multicentre randomised controlled trial. Lancet 2013;382:516-524.

63. Collaboration CT, Dennis M, Sandercock P, Reid J, Graham C, Murray $G$, et al. The effect of graduated compression stockings on long-term outcomes after stroke: the CLOTS trials 1 and 2. Stroke 2013;44:1075-1079.

64. Collaboration CT, Dennis M, Sandercock PA, Reid J, Graham C, Murray $G$, et al. Effectiveness of thigh-length graduated compression stockings to reduce the risk of deep vein thrombosis after stroke (CLOTS trial 1): a multicentre, randomised controlled trial. Lancet 2009;373:1958-1965.

65. Paciaroni M, Agnelli G, Venti M, Alberti A, Acciarresi M, Caso $V$. Efficacy and safety of anticoagulants in the prevention of venous thromboembolism in patients with acute cerebral hemorrhage: a meta-analysis of controlled studies. J Thromb Haemost 2011;9:893-898.

66. Guyatt GH, Akl EA, Crowther M, Gutterman DD, Schuunemann HJ, American College of Chest Physicians Antithrombotic T, et al. Executive summary: Antithrombotic Therapy and Prevention of Thrombosis, 9th ed: American College of Chest Physicians Evidence-Based Clinical Practice Guidelines. Chest 2012;141:7S-47S.

67. Kamel H, Hemphill JC 3rd. Characteristics and sequelae of intracranial hypertension after intracerebral hemorrhage. Neurocrit Care 2012;17:172-176.

68. Kamel H, Navi BB, Nakagawa K, Hemphill JC 3rd, Ko NU. Hypertonic saline versus mannitol for the treatment of elevated intracranial pressure: a meta-analysis of randomized clinical trials. Crit Care Med 2011;39:554-559.

69. Poungvarin N, Bhoopat $W$, Viriyavejakul $A$, Rodprasert $P$, Buranasiri $P$, Sukondhabhant $S$, et al. Effects of dexamethasone in primary supratentorial intracerebral hemorrhage. $N$ Engl J Med 1987;316:1229-1233.

70. Schwarz S, Hafner K, Aschoff A, Schwab S. Incidence and prognostic significance of fever following intracerebral hemorrhage. Neurology 2000;54:354-361.

71. Kollmar R, Staykov D, Dorfler A, Schellinger PD, Schwab S, Bardutzky J. Hypothermia reduces perihemorrhagic edema after intracerebral hemorrhage. Stroke 2010;41:1684-1689.

72. Fingas M, Penner M, Silasi G, Colbourne F. Treatment of intracerebral hemorrhage in rats with $12 h, 3$ days and 6 days of selective brain hypothermia. Exp Neurol 2009;219:156-162.

73. Fogelholm R, Murros K, Rissanen A, Avikainen S. Admission blood glucose and short term survival in primary intracerebral haemorrhage: a population based study. J Neurol Neurosurg Psychiatry 2005;76:349-353.
74. Investigators N-SS, Finfer S, Chittock DR, Su SY, Blair D, Foster $\mathrm{D}$, et al. Intensive versus conventional glucose control in critically ill patients. N Engl J Med 2009;360:1283-1297.

75. Vespa P, Boonyaputthikul R, McArthur DL, Miller C, Etchepare $M$, Bergsneider $M$, et al. Intensive insulin therapy reduces microdialysis glucose values without altering glucose utilization or improving the lactate/pyruvate ratio after traumatic brain injury. Crit Care Med 2006;34:850-856.

76. Bladin CF, Alexandrov AV, Bellavance A, Bornstein N, Chambers $B$, Cote $R$, et al. Seizures after stroke: a prospective multicenter study. Arch Neurol 2000;57:1617-1622.

77. Claassen J, Jette $N$, Chum F, Green R, Schmidt M, Choi $H_{\text {, et }}$ al. Electrographic seizures and periodic discharges after intracerebral hemorrhage. Neurology 2007;69:1356-1365.

78. Szaflarski JP, Rackley AY, Kleindorfer D0, Khoury J, Woo D, Miller $R$, et al. Incidence of seizures in the acute phase of stroke: a population-based study. Epilepsia 2008;49:974-981.

79. Beghi E, D'Alessandro R, Beretta S, Consoli D, Crespi V, Delaj $\mathrm{L}$, et al. Incidence and predictors of acute symptomatic seizures after stroke. Neurology 2011;77:1785-1793.

80. De Herdt V, Dumont F, Henon H, Derambure P, Vonck K, Leys $D$, et al. Early seizures in intracerebral hemorrhage: incidence, associated factors, and outcome. Neurology 2011;77:17941800.

81. Lyden PD, Shuaib A, Lees KR, Davalos A, Davis SM, Diener HC, et al. Safety and tolerability of NXY-059 for acute intracerebral hemorrhage: the CHANT Trial. Stroke 2007;38:22622269.

82. Maramattom BV, Weigand S, Reinalda M, Wijdicks EF, Manno EM. Pulmonary complications after intracerebral hemorrhage. Neurocrit Care 2006;5:115-119.

83. Hinchey JA, Shephard T, Furie K, Smith D, Wang D, Tonn S, et al. Formal dysphagia screening protocols prevent pneumonia. Stroke 2005;36:1972-1976.

84. Holloway RG, Arnold RM, Creutzfeldt CJ, Lewis EF, Lutz BJ, McCann RM, et al. Palliative and end-of-life care in stroke: a statement for healthcare professionals from the American Heart Association/American Stroke Association. Stroke 2014; 45:1887-1916.

85. Da Pian R, Bazzan A, Pasqualin A. Surgical versus medical treatment of spontaneous posterior fossa haematomas: a cooperative study on 205 cases. Neurol Res 1984;6:145-151.

86. Firsching $R$, Huber $M$, Frowein RA. Cerebellar haemorrhage: management and prognosis. Neurosurg Rev 1991;14:191-194.

87. Komiyama $M$, Boo $Y E$, Yagura $H$, Yasui $T$, Baba $M$, Hakuba $A$, et al. A clinical analysis of 32 brainstem haemorrhages; with special reference to surviving but severely disabled cases. Acta Neurochir (Wien) 1989;101:46-51. 
88. Manno EM, Atkinson JL, Fulgham JR, Wijdicks EF. Emerging medical and surgical management strategies in the evaluation and treatment of intracerebral hemorrhage. Mayo Clin Proc 2005;80:420-433.

89. Hara $T$, Nagata $K$, Kawamoto $S$, Sashida J, Abe $T$, Wada $A$, et al. [Functional outcome of primary pontine hemorrhage: conservative treatment or stereotaxic surgery]. No Shinkei Geka 2001;29:823-829.

90. Mangiardi JR, Epstein FJ. Brainstem haematomas: review of the literature and presentation of five new cases. J Neurol Neurosurg Psychiatry 1988;51:966-976.

91. Takahama H, Morii K, Sato M, Sekiguchi K, Sato S. [Stereotactic aspiration in hypertensive pontine hemorrhage: comparative study with conservative therapy]. No Shinkei Geka 1989;17: 733-739.

92. Mendelow AD, Gregson BA, Fernandes HM, Murray GD, Teasdale GM, Hope DT, et al. Early surgery versus initial conservative treatment in patients with spontaneous supratentorial intracerebral haematomas in the International Surgical Trial in Intracerebral Haemorrhage (STICH): a randomised trial. Lancet 2005;365:387-397.

93. Mendelow AD, Gregson BA, Rowan EN, Murray GD, Gholkar $A$, Mitchell PM, et al. Early surgery versus initial conservative treatment in patients with spontaneous supratentorial lobar intracerebral haematomas (STICH II): a randomised trial. Lancet 2013;382:397-408.

94. Fung $C$, Murek M, Z'Graggen WJ, Krahenbuhl AK, Gautschi $O P$, Schucht $P$, et al. Decompressive hemicraniectomy in patients with supratentorial intracerebral hemorrhage. Stroke 2012;43:3207-3211.

95. Hayes SB, Benveniste RJ, Morcos JJ, Aziz-Sultan MA, Elhammady MS. Retrospective comparison of craniotomy and decompressive craniectomy for surgical evacuation of nontraumatic, supratentorial intracerebral hemorrhage. Neurosurg Focus 2013;34:E3.

96. Heuts $S G$, Bruce $S S$, Zacharia BE, Hickman ZL, Kellner $C P$, Sussman ES, et al. Decompressive hemicraniectomy without clot evacuation in dominant-sided intracerebral hemorrhage with ICP crisis. Neurosurg Focus 2013;34:E4.

97. Takeuchi S, Wada K, Nagatani K, Otani N, Mori K. Decompressive hemicraniectomy for spontaneous intracerebral hemorrhage. Neurosurg Focus 2013;34:E5.

98. Auer LM, Deinsberger W, Niederkorn K, Gell G, Kleinert R, Schneider $G$, et al. Endoscopic surgery versus medical treat- ment for spontaneous intracerebral hematoma: a randomized study. J Neurosurg 1989;70:530-535.

99. Morgan T, Zuccarello M, Narayan R, Keyl P, Lane K, Hanley D. Preliminary findings of the minimally-invasive surgery plus rtPA for intracerebral hemorrhage evacuation (MISTIE) clinical trial. Acta Neurochir Supp/ 2008;105:147-151.

100. Mould WA, Carhuapoma JR, Muschelli J, Lane K, Morgan TC, McBee NA, et al. Minimally invasive surgery plus recombinant tissue-type plasminogen activator for intracerebral hemorrhage evacuation decreases perihematomal edema. Stroke 2013;44:627-634.

101. Wang WZ, Jiang B, Liu HM, Li D, Lu CZ, Zhao YD, et al. Minimally invasive craniopuncture therapy vs. conservative treatment for spontaneous intracerebral hemorrhage: results from a randomized clinical trial in China. Int J Stroke 2009;4:11-16.

102. Gregson BA, Broderick JP, Auer LM, Batjer H, Chen XC, Juvela $S$, et al. Individual patient data subgroup meta-analysis of surgery for spontaneous supratentorial intracerebral hemorrhage. Stroke 2012;43:1496-1504.

103. Morgenstern LB, Demchuk AM, Kim DH, Frankowski RF, Grotta JC. Rebleeding leads to poor outcome in ultra-early craniotomy for intracerebral hemorrhage. Neurology 2001;56:12941299.

104. Hallevi H, Albright KC, Aronowski J, Barreto AD, Martin-Schild $S$, Khaja AM, et al. Intraventricular hemorrhage: Anatomic relationships and clinical implications. Neurology 2008;70:848852.

105. Morgan T, Awad I, Keyl P, Lane K, Hanley D. Preliminary report of the clot lysis evaluating accelerated resolution of intraventricular hemorrhage (CLEAR-IVH) clinical trial. Acta Neurochir Supp/ 2008;105:217-220.

106. Naff N, Williams MA, Keyl PM, Tuhrim S, Bullock MR, Mayer $\mathrm{SA}$, et al. Low-dose recombinant tissue-type plasminogen activator enhances clot resolution in brain hemorrhage: the intraventricular hemorrhage thrombolysis trial. Stroke 2011;42: 3009-3016.

107. Bai Y, Hu Y, Wu Y, Zhu Y, He Q, Jiang C, et al. A prospective, randomized, single-blinded trial on the effect of early rehabilitation on daily activities and motor function of patients with hemorrhagic stroke. J Clin Neurosci 2012;19:1376-1379.

108. Cumming TB, Thrift AG, Collier JM, Churilov L, Dewey HM, Donnan $\mathrm{GA}$, et al. Very early mobilization after stroke fasttracks return to walking: further results from the phase II AVERT randomized controlled trial. Stroke 2011;42:153-158. 